\title{
Complete endoscopic mucosal resection of malignant colonic sessile polyps and clinical outcome of 51 cases
}

\author{
Maria Fragakia , Evangelos Voudoukis a , Evdoxia Chliarab, loannis Dimas ${ }^{a}$, Afroditi Mpitoulia, \\ Magdalini Velegraki ${ }^{a}$, Emmanouil Vardas ${ }^{a}$, Angeliki Theodoropoulou ${ }^{a}$, Konstantinos Karmiris ${ }^{a}$, \\ Linda Giannikakib, Gregorios Paspatis ${ }^{a}$
}

Venizeleion General Hospital, Heraklion, Crete, Greece

Abstract

\section{Introduction}

The term "malignant polyp" refers to an adenoma with a benign endoscopic appearance [1] and a histology report that suggests malignancy invading into the submucosa [1-3]. A malignant polyp is therefore classified as an early carcinoma.

Department of ${ }^{a}$ Gastroenterology (Maria Fragaki, Evangelos Voudoukis, Ioannis Dimas, Afroditi Mpitouli, Magdalini Velegraki, Emmanouil Vardas, Angeliki Theodoropoulou, Konstantinos Karmiris,

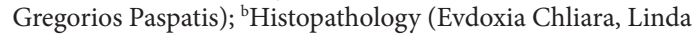
Giannikaki), Venizeleion General Hospital, Heraklion, Greece

Conflict of Interest: None

Correspondence to: Gregorios Paspatis, Knossou 44, Heraklion, Greece, e-mail: gpaspatis@gmail.com

Received 2 October 2018; accepted 26 November 2018; published online 21 December 2018

DOI: https://doi.org/10.20524/aog.2018.0343
These account for $0.75-5.6 \%$ of large bowel polyps removed in screening colonoscopies [1].

The management of a malignant polyp following endoscopic removal is controversial, because of the supposed increased risk of residual malignant cells within the bowel wall and the increased rate of lymph node metastasis (LNM) [4,5]. The most commonly identified risk factors for LNM are submucosal invasion depth, lymphovascular invasion, poor tumor differentiation, presence of tumor budding (the presence of isolated single cells or small clusters of fewer than 5 cells scattered at the leading edge of the invasion $[6,7]$ ) and positive resection margin status (dysplastic cells to distance $\leq 1 \mathrm{~mm}$ from polyp excision margins) [3-5]. In low-risk patients, with none of the aforementioned factors and submucosal invasion $<1 \mathrm{~mm}$ from muscularis mucosae, the risk of LNM in malignant polyps has been reported to be insignificant (0-1.2\%); thus, endoscopic resection alone seems to be an adequate treatment [8-10]. Meta-analyses and guidelines recommend that deep submucosal invasion $(>1 \mathrm{~mm})$ in 
malignant colonic polyps is an important risk factor for residual malignant disease and LNM (8-25\%) [4,5,8,11]. However, existing data are based on small retrospective studies with marked heterogeneity [3-5,12,13].

The primary aim of this study was to investigate the longterm outcome of patients who underwent complete endoscopic mucosal resection (EMR) of malignant colonic sessile polyps invading the submucosal layer of the bowel wall. Secondary outcomes included the evaluation of other polyp parameters, such as lymphovascular invasion, tumor differentiation, resection margin status, and the presence of tumor budding in the long-term outcome of those patients.

\section{Patients and methods}

From January 2000 to December 2016 a retrospective review of the endoscopy records was conducted in Venizeleion General Hospital, which is a tertiary referral center in Crete, Greece. The study was approved by the Institutional Ethics Review Board of our Hospital. All enrolled patients exhibited a malignant colonic sessile polyp, completely endoscopically resected. Patient's age, sex, polyp size (estimated by visual comparison to the opening width of biopsy forceps) and location (right colon was defined the part proximal to the splenic flexure) were recorded. According to the Paris classification all polyps were classified as Is [14]. Complete polyp resection was endoscopically confirmed after the completion of polypectomy. Lesions with incomplete resection were excluded. Piecemeal resection was performed in large lesions when en bloc resection could not be applied. Experienced endoscopists, each of them with more than 3000 colonoscopies, performed all procedures. A variety of snares were used, including the Snare Master snare (Olympus) and the Captivator-II snare (Boston Scientific), with sizes ranging between 10 and $30 \mathrm{~mm}$. For EMR a methylene blue-tinted normal saline solution was injected into the submucosal space, underneath the lesion, using a 25-G needle. Cautery was applied with monopolar coagulation current, using the ERBE ICC200 or the ERBE VIO200D in the fractionated cutting mode ENDO CUT Q.

Histological features of the polyps were also recorded. This included the depth of submucosal invasion (less or more than $1 \mathrm{~mm}$ ) (Fig. 1), the presence of lymphovascular invasion, tumor differentiation according to the World Health Organization's classification (well-, moderately-, or poorly-differentiated) [15], tumor budding, and resection margin status.

Computed tomography (CT) or magnetic resonance imaging (MRI) scanning was performed as a regular workup in all patients before any decision on further management. All patients were informed about their condition and surgery was advised. Some of them opted for further surgical treatment and others preferred conservative management with repeat colonoscopies at 3-6 and 12 months, oncologic consultation and further follow-up CT and/or MRI studies. In most cases, oncologist suggested imaging at 6 months after resection and every year after that for 5 years, combined with oncologic consultation over the same period. In recent years, a tattoo was placed next to the polypectomy site, according to current guidelines [1].

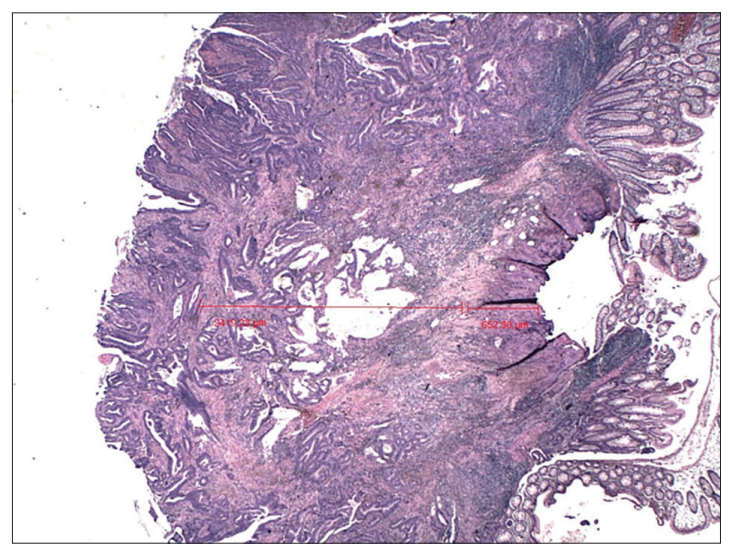

Figure 1 Submucosal invasion $>1 \mathrm{~mm}$ in a patient who chose endoscopic follow up

Table 1 Demographic characteristics of the 51 patients and histological characteristics of the sessile malignant polyps

\begin{tabular}{lc} 
Characteristic & Value \\
\hline Age (years), & $70(17,38-88)$ \\
Median (IQR, range) & \\
Sex (\%) & \\
$\quad$ Male & $28(54.9)$ \\
Female & $23(45.1)$ \\
Tumor size & \\
$>20$ mm & $30(58.8)$ \\
$\leq 20$ mm & $21(41.2)$ \\
Location & \\
Rectum & $15(29.4)$ \\
Left colon & $29(56.9)$ \\
Right colon & $7(13.7)$ \\
Resection method & \\
En bloc & $21(41.2)$ \\
Piecemeal & $30(58.8)$ \\
Submucosal invasion & \\
$\quad \leq 1$ mm & $7(13.7)$ \\
$>1$ mm & $44(86.3)$ \\
Resection margin status (mm) & \\
Median (IQR, range) & $1(1.7,0-7)$ \\
Lymphovascular invasion & $7(13.7)$ \\
Tumor differentiation & \\
Well-differentiated & $14(27.5)$ \\
Moderately-differentiated & $28(54.9)$ \\
Poorly-differentiated & $9(17.6)$ \\
\hline Tumor budding & $9(17.6)$ \\
\hline IQR, interquartile range & \\
\hline &
\end{tabular}

\section{Statistical analysis}

Medians with interquartile range (IQR) were calculated for continuous data and percentages were computed for discrete data. The Kolmogorov-Smirnov test was used to evaluate distribution normality. Continuous variables were compared using Student's $t$ or Mann-Whitney tests as appropriate. Statistical significance was defined as $\mathrm{P} \leq 0.05$. 
Table 2 Characteristics of the EMR only and EMR+surgery groups and histological characteristics of the sessile malignant polyps

\begin{tabular}{|c|c|c|}
\hline Variable & $\begin{array}{c}\text { EMR only } \\
(\mathrm{n}=19), \mathrm{n}(\%)\end{array}$ & $\begin{array}{l}\text { EMR+surgery } \\
(\mathrm{n}=32), \mathrm{n}(\%)\end{array}$ \\
\hline $\begin{array}{l}\text { Age (years), } \\
\text { Median (IQR, range) }\end{array}$ & $72(15,53-88)$ & $69(21,38-87)$ \\
\hline $\begin{array}{l}\text { Sex }(\%) \\
\text { Male } \\
\text { Female }\end{array}$ & $\begin{array}{c}7(36.8) \\
12(63.2)\end{array}$ & $\begin{array}{l}21(65.6) \\
11(34.4)\end{array}$ \\
\hline $\begin{array}{l}\text { Tumor size } \\
>20 \mathrm{~mm} \\
\leq 20 \mathrm{~mm}\end{array}$ & $\begin{array}{l}11(57.9) \\
8(42.1)\end{array}$ & $\begin{array}{l}19(59.4) \\
13(40.6)\end{array}$ \\
\hline $\begin{array}{l}\text { Location } \\
\text { Rectum } \\
\text { Left colon } \\
\text { Right colon }\end{array}$ & $\begin{array}{c}10(52.6) \\
9(47.4) \\
-\end{array}$ & $\begin{array}{c}5(15.6) \\
20(62.5) \\
7(21.9)\end{array}$ \\
\hline $\begin{array}{l}\text { Resection method } \\
\text { En bloc } \\
\text { Piecemeal }\end{array}$ & $\begin{array}{c}3(15.8) \\
16(84.2)\end{array}$ & $\begin{array}{l}18(56.3) \\
14(43.8)\end{array}$ \\
\hline $\begin{array}{l}\text { Submucosal invasion } \\
\leq 1 \mathrm{~mm} \\
>1 \mathrm{~mm}\end{array}$ & $\begin{array}{c}2(10.5) \\
17(89.5)\end{array}$ & $\begin{array}{c}5(15.6) \\
27(84.4)\end{array}$ \\
\hline $\begin{array}{l}\text { Resection margin status (mm) } \\
\text { Median (IQR, range) }\end{array}$ & $1(1.3,0-4)$ & $0,65(1.1,0-7)$ \\
\hline Lymphovascular invasion & 0 & $7(21.9)$ \\
\hline $\begin{array}{l}\text { Tumor differentiation } \\
\text { Well-differentiated } \\
\text { Moderately-differentiated } \\
\text { Poorly-differentiated }\end{array}$ & $\begin{array}{l}7(36.8) \\
9(47.4) \\
3(15.8)\end{array}$ & $\begin{array}{c}7(21.9) \\
19(59.4) \\
6(18.8)\end{array}$ \\
\hline Tumor budding & $4(21.1)$ & $5(15.6)$ \\
\hline
\end{tabular}

EMR, endoscopic mucosal resection; IQR, interquartile range

\section{Results}

Fifty-one patients with confirmed infiltrative adenocarcinoma in sessile colonic polyps who had undergone EMR were retrospectively identified and included in the study. The demographic and clinical characteristics of the patients are summarized in Table 1. A total of 32 (62.7\%) patients underwent surgery after EMR, and 19 (37.3\%) chose endoscopic follow up. All patients with lymphovascular invasion underwent surgery. None of the patients in the EMR group had lymphovascular invasion. The characteristics of the two groups are shown in Table 2.

In $44(86.3 \%)$ patients the submucosal invasion was $>1 \mathrm{~mm}$. After surgery, residual malignant disease was identified in the surgical pathological specimen of only 1 patient. This sessile polyp, located in the left colon, was less than $10 \mathrm{~mm}$ in size, moderately differentiated with a submucosal invasion $>1 \mathrm{~mm}$, and with no evidence of tumor budding or lymphovascular invasion. With a median follow up of 23.41 months (IQR 33.4, range 1.84-144.92), no local recurrences or LNM were identified. Forty-nine patients are alive without evidence of disease and 2 died from other causes (without evidence of disease at last follow up).

\section{Discussion}

This study suggests that, even in cases of malignant colonic sessile polyps with submucosal invasion $>1 \mathrm{~mm}$ and the presence of other high-risk features (lymphovascular invasion, tumor budding), complete EMR might be a sufficient treatment. This finding, if confirmed by larger studies, can be of vital importance, especially in high-risk groups of patients, such as the elderly, and in those with polyps located in the lower rectum, where surgery is not always a favorable option.

Recently, the European Society of Gastrointestinal Endoscopy published polypectomy guidelines suggesting the need for measurement of the submucosal invasion depth, in addition to other histological risk factors-without, however, clearly stating the exact invasion depth beyond which patients need to undergo additional surgery [3]. Results from studies show mixed results regarding the long-term safety of the invasion depth. According to Oka et al [16], a systemic review [5] and a meta-analysis from the United Kingdom [4], submucosal invasion $<1 \mathrm{~mm}$ is a reliable histopathological criterion associated with a negligible risk of LNM or recurrence. On the other hand, Nakadoi et al [9] extended the safe submucosal invasion depth to $1.8 \mathrm{~mm}$ and Han et al [17] to $1.9 \mathrm{~mm}$ as an independent factor for LNM. Although invasion depth represents the most frequent indication for subsequent surgery, there are studies that suggest other polyp features (tumor differentiation, budding and resection margin status) might be more important predictors than submucosal invasion regarding the necessity for subsequent surgery $[9,17,18]$. Our data support the extension of the submucosal invasion depth of $>1 \mathrm{~mm}$ for patients who require additional surgery. Furthermore, since residual malignant disease was identified in only 1 surgical specimen, it is rather difficult to evaluate the role of the other parameters in terms of residual disease and risk of recurrence. In addition, another important factor to evaluate is the location of the malignant sessile polyp. A study from Japan points out that high-risk submucosal rectal cancer should be surgically resected, given its higher risk for recurrence [19], but since no recurrence was identified in our patients $(\mathrm{N}=15)$ we are unable to further evaluate this factor.

A systemic review by Bosch et al pointed out that lymphatic invasion was the most powerful predictor of LNM (relative risk [RR] 5.2, 95\% confidence interval [CI] 4.0-6.8), vascular invasion was a much weaker predictor of LNM (RR 2.2, 95\%CI 1.4-3.2), whereas lymphovascular invasion had an intermediate relative risk (RR 3.9, 95\% CI 2.7-5.6) [5]. It is important to point out that in our study none of the endoscopically treated patients had lymphovascular invasion; this might be an explanation of the favorable results of this group.

Novel endoscopic methods that provide complete en bloc resection, such as endoscopic submucosal dissection and full thickness resection, can lower the rate of unnecessary additional surgery [20,21], but these were not applicable in our department, especially in the early years of the study period. Moreover, a recently published study from Japan proposed the use of a new artificial intelligence model as a predictor of LNM after endoscopic resection of T1 colorectal cancers [22].

Our study had certain limitations. First, it was a retrospective study conducted in a single tertiary institute with a limited 
number of cases. Second, there was some heterogeneity in the polypectomy techniques and technology utilized over all these years. New polypectomy guidelines have recently been established, based on newly evolving endoscopic technology and more advanced EMR techniques, developed and used throughout that period. Third, the follow-up period is still rather short to assess both late disease recurrence events and, in particular, LNM.

In conclusion, even in cases with submucosal invasion $>1 \mathrm{~mm}$ and the presence of other high-risk features (lymphovascular invasion, tumor budding), complete EMR may be an adequate treatment for malignant invasive colonic sessile polyps. However, because of the risk of LNM, surgical resection is still the gold standard for patients with malignant invasive colonic sessile polyps and endoscopic resection alone should only be considered for patients who are unfit for surgery or refuse it. Our data require further validation from larger, prospective, multicenter studies, which will examine in more detail the features of resected malignant polyps in order to possibly redefine criteria for preventing unnecessary colectomies without compromising oncological safety.

\section{Summary Box}

\section{What is already known:}

- Malignant sessile polyps have an increased rate of lymph node metastases (LNM)

- Deep submucosal invasion $(>1 \mathrm{~mm})$ in malignant polyps is an important risk factor for residual malignant disease and LNM

\section{What the new findings are:}

- Malignant sessile polyps with submucosal invasion $>1 \mathrm{~mm}$ can be treated endoscopically

- If confirmed by larger prospective studies, this might influence the treatment strategy, particularly in patients with significant comorbidities

\section{References}

1. Williams JG, Pullan RD, Hill J, et al; Association of Coloproctology of Great Britain and Ireland. Management of the malignant colorectal polyp: ACPGBI position statement. Colorectal Dis 2013;15 Suppl 2:1-38.

2. Neilson LJ, Rutter MD, Saunders BP, Plumb A, Rees CJ. Assessment and management of the malignant colorectal polyp. Frontline Gastroenterol 2015;6:117-126.

3. Ferlitsch M, Moss A, Hassan C, et al. Colorectal polypectomy and endoscopic mucosal resection (EMR): European Society of Gastrointestinal Endoscopy (ESGE) Clinical Guideline. Endoscopy 2017;49:270-297.

4. Beaton C, Twine CP, Williams GL, Radcliffe AG. Systematic review and meta-analysis of histopathological factors influencing the risk of lymph node metastasis in early colorectal cancer. Colorectal Dis 2013; 15:788-797.

5. Bosch SL, Teerenstra S, de Wilt JH, Cunningham C, Nagtegaal ID. Predicting lymph node metastasis in pT1 colorectal cancer: a systematic review of risk factors providing rationale for therapy decisions. Endoscopy 2013;45:827-834.

6. Ueno H, Murphy J, Jass JR, Mochizuki H, Talbot IC. Tumour 'budding' as an index to estimate the potential of aggressiveness in rectal cancer. Histopathology 2002;40:127-132.

7. Hase K, Shatney C, Johnson D, Trollope M, Vierra M. Prognostic value of tumor "budding" in patients with colorectal cancer. Dis Colon Rectum 1993;36:627-635.

8. Nascimbeni R, Burgart LJ, Nivatvongs S, Larson DR. Risk of lymph node metastasis in T1 carcinoma of the colon and rectum. Dis Colon Rectum 2002;45:200-206.

9. Nakadoi K, Tanaka S, Kanao H, et al. Management of T1 colorectal carcinoma with special reference to criteria for curative endoscopic resection. J Gastroenterol Hepatol 2012;27:1057-1062.

10. Kitajima K, Fujimori T, Fujii S, et al. Correlations between lymph node metastasis and depth of submucosal invasion in submucosal invasive colorectal carcinoma: a Japanese collaborative study. J Gastroenterol 2004;39:534-543.

11. Butte JM, Tang P, Gonen M, et al. Rate of residual disease after complete endoscopic resection of malignant colonic polyp. Dis Colon Rectum 2012;55:122-127.

12. Choi JY, Jung SA, Shim KN, et al; Korean ESD Study Group. Metaanalysis of predictive clinicopathologic factors for lymph node metastasis in patients with early colorectal carcinoma. J Korean Med Sci 2015;30:398-406.

13. Mou S, Soetikno R, Shimoda T, Rouse R, Kaltenbach T. Pathologic predictive factors for lymph node metastasis in submucosal invasive (T1) colorectal cancer: a systematic review and metaanalysis. Surg Endosc 2013;27:2692-2703.

14. The Paris endoscopic classification of superficial neoplastic lesions: esophagus, stomach, and colon: November 30 to December 1, 2002. Gastrointest Endosc 2003;58:S3-S43.

15. Bosman FT, World Health Organization, International Agency for Research on Cancer. WHO classification of tumours of the digestive system. IARC 2010;134-146.

16. Oka S, Tanaka S, Kanao $\mathrm{H}$, et al. Mid-term prognosis after endoscopic resection for submucosal colorectal carcinoma: summary of a multicenter questionnaire survey conducted by the colorectal endoscopic resection standardization implementation working group in Japanese Society for Cancer of the Colon and Rectum. Dig Endosc 2011;23:190-194.

17. Han J, Hur H, Min BS, Lee KY, Kim NK. Predictive factors for lymph node metastasis in submucosal invasive colorectal carcinoma: a new proposal of depth of invasion for radical surgery. World J Surg 2018;42:2635-2641.

18. Belderbos TD, van Erning FN, de Hingh IH, van Oijen MG, Lemmens VE, Siersema PD. Long-term recurrence-free survival after standard endoscopic resection versus surgical resection of submucosal invasive colorectal cancer: a population-based study. Clin Gastroenterol Hepatol 2017;15:403-411.

19. Ikematsu H, Yoda Y, Matsuda T, et al. Long-term outcomes after resection for submucosal invasive colorectal cancers. Gastroenterology 2013;144:551-559; quiz e14.

20. Pimentel-Nunes P, Dinis-Ribeiro M, Ponchon T, et al. Endoscopic submucosal dissection: European Society of Gastrointestinal Endoscopy (ESGE) Guideline. Endoscopy 2015;47:829-854.

21. Al-Bawardy B, Rajan E, Wong Kee Song LM. Over-the-scope clip-assisted endoscopic full-thickness resection of epithelial and subepithelial GI lesions. Gastrointest Endosc 2017;85:1087-1092.

22. Ichimasa K, Kudo SE, Mori Y, et al. Artificial intelligence may help in predicting the need for additional surgery after endoscopic resection of T1 colorectal cancer. Endoscopy 2018;50:230-240. 